\title{
A Kano-Based Quick-Response Product Configuration System Under Industry 4.0
}

\author{
Ching-Hung LEE ${ }^{\mathrm{a} 1}$, Fan Li ${ }^{\mathrm{b}}$, Chun-Hsien CHEN ${ }^{\mathrm{b}, \mathrm{c}}$ and Chenyu LIN ${ }^{\mathrm{b}}$ \\ ${ }^{a}$ School of Public Policy and Administration, Xi'an Jiaotong University, China 710049 \\ ${ }^{\mathrm{b}}$ School of Mechanical and Aerospace Engineering, Nanyang Technological \\ University, Singapore 639798 \\ ${ }^{c}$ Delta-NTU Corporate Laboratory for Cyber-Physical System, School of Electrical and \\ Electronic Engineering, Nanyang Technological University, Singapore 639798
}

\begin{abstract}
Based on Cyber physical system (CPS) and the Internet of things (IoT), the smart production system is capable to suit diverse customers' manufacturing requirements. It has the potential to provide digital configure-to-order (CTO) services in a quick response time. To achieve this potential, a new conceptualization of quick-response product configuration system, which translates the voice of customers to technical specifications, is proposed. It is expected that the proposed system can enhance the communication between the customers and the manufacturers. We adopt the Kano model to receive the voice of customers as inputs and generate a product configuration as outputs which can meet customer's requirements. A case study and a product configure system for ordering assistance are demonstrated in this work.
\end{abstract}

Keywords. Kano Model, Product Configuration System, Order Acquisition and Fulfilment, Industry 4.0 .

\section{Introduction}

The emergence of the Internet-of-things (IoT) enables coordination and integration across the whole manufacturing process, transforming traditional factories into smart factories by cyber-physical system (CPS). A smart factory consists of smart machines, warehousing systems, and production facilities. All modules are deeply intertwined, exhibiting multiple and distinct actions and controls on each other [1]. The smart factories allow individual customer requirements to be met and make the production even in very low volumes but still profitable. The new way of production, exposing manufacturing companies to a new environment with opportunities and threats. Specifically, it is important for such companies to make wise decisions in short response time to succeed in the global market. It is a serious issue about how a company responds in the new environment and how to distribute their resources to optimize production and product transactions within their capability [2]. The key to success is to quickly and effectively react to diverse and dynamic customer requirements and to bring the customized products in a shorter time to market [3][4]. To achieve that, a product configuration system plays an important role, which bridges the gap between customers and manufacturers by selectable predefined attributes within enterprise capability. The

\footnotetext{
${ }^{1}$ Corresponding Author, Email: burning0831@gmail.com.
} 
implementation of the product configuration system helps to significantly reduce errors in the configurations released by the sales department. Though many related works about product configuration system have been studied, there still lacks studies adopting product configuration system in Industry 4.0 (I 4.0) and refining methodologies for quickresponse and mass customization to demonstrate new scenarios in I 4.0.

Aiming to bridge this gap with multidisplinary methods by Kano model and system design, this paper (1) analyzes typical and current manufacturing scenarios with a case study in an international electronic company, (2) addresses the customer preference by Kano model, (3) takes the results of Kano model as an important parameter in the new quick-response product configuration system design. The rest of this paper is organized as follows. Section 1 presents a brief literature review of Kano model application in the design area, and Section 2 introduces the background of the case company about its current product configuration system. Section3 presents the work of adopting Kano questionnaire to obtain customer preference in selecting a laptop. Section 4 demonstrates the design of a new quick-response product configuration system for order assistance which can be customized by selecting the product attributes based on customer preference respectively. Finally, Section 5 summarizes the overall work and discusses the possible research directions in the future.

\section{Literature review}

Kano (1984) proposed the non-linear relationship between quality attribute performance and overall satisfaction. According to the Kano's model, quality attributes can be classified into six categories i.e. One-dimensional (O), Attractive (A), Must-be (M), Indifferent (I), Reverse (R), Questionable (Q) [5]. The categorie of a quality attribute depends on the customer satisfaction (CS) level and customer requirements (CRs) fulfillment levels. The Kano's model is conducted through 3 procedures: Kano investigation, Kano evaluation, and Kano categorization. The Kano questions examine each CR with a pair of questions, in functional form and dysfunctional form, and each answer pair is aligned with the Kano evaluation table (as shown in Table 1). Many Kano model related works have been conducted in identifying customer satisfaction and customer requirements in product design fields. Ji et al. (2014) [6] adopted Kano model for identifying customer satisfaction (CS) at different CR fulfilment level to enhance product design. Violante and Vezzetti (2017) [7] proposed a novel assessment matrix that identifies the relationships and classifications requirements between different Kano qualitative and quantitative approaches to assist in selecting the most suitable methodology that response better in customer-driven product and service design. Kano model is a suitable and practical model to capture customer requirements by assessing their satisfaction [8][9]. Abundant refined Kano qualitative and quantitative approaches abound in the literature. However, there has far been relatively little research into the customized order fulliment and product configuration area under the background of Industry $4.0[10][11][12][13][14]$.

\section{Current (As-is) model of order acquisition process}

Company $\mathrm{C}$ is a leading industrial automation manufacturer, offering efficient and reliable products and solutions to serve global customers. One of their specialty is an 
automated batch process for small volume with high mix customization. It has a loyal client, Company A, for years. Company A is a business-to-business (B2B) information technology (IT) company, specializing in the flexible manufacturing of desktop, laptops and other IT devices. Established for years, A has been running smoothly with its standard operating procedure, including sale interview with their clients. However, recently, they have been receiving increasingly frequent customized orders in a greater diversity from their client, Company A. Company B is a laptop retailer, which is supplied mainly by Company A. In their standard collaborative process, individual consumers visited Company B's outlet, expressed their needs to B's sales personnel and hoped to get a desirable product. If their needs are beyond the existing products available in shops, B's sales personnel would inform the procurement team to place the customized order. The procurement team would then engage Company B's sales personnel for an interview to discuss the cost and the feasibility of the customization. At this point, A's sales personnel would also seek technical advice from A's technical personnel to validate the feasibility. Along with this communication chain, information might be misaligned sometimes. A diagram is developed to help the understanding of this communication chain as shown in Figure 1.

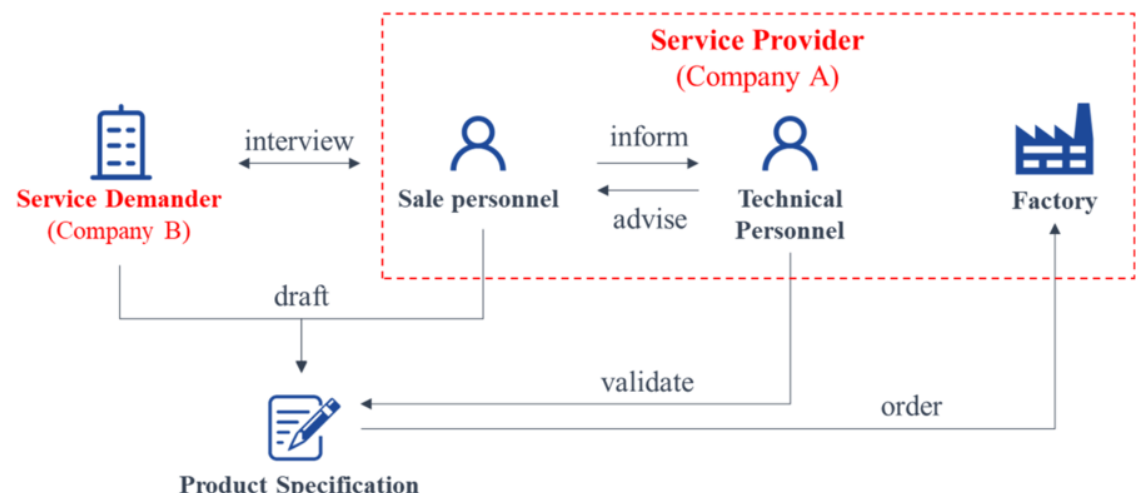

Figure 1. As-is model of order acquisition process

In recent years, B noticed that the consumers expectations have gone more diverse. The communication activities between $\mathrm{A}$ and $\mathrm{B}$ became more frequently, and thus, more severe misalign of information was observed. Both A and B agreed that the current process had consumed a considerable amount of manpower and showed inefficiency when the communication becomes more intensive. They were keen to find a solution to address this issue. In addition, Company $B$ also noticed that there could be a communication barrier between A' sales personnel and B's procurement team. Neither of them knows how to translate the customer needs to engineering characteristics. For instance, they may want the laptop to be good at graphics processing, but they have no idea which graphics card is capable enough to satisfy the need. Apparently, the best way to recommend the optimal laptop configuration is having direct communication with A's technical personnel. But it requires much more manpower and incurs more workload on the technical personnel. Therefore, Company B engaged Company $\mathrm{C}$ to streamline the communication process. $\mathrm{C}$ wishes to propose a recommendation system, which takes the customer's evaluation priority or weight as the input, to generate the optimal product configuration under the given budget condition. 


\section{Application of the Kano's Model on Customer Requirements}

A Kano questionnaire is developed to investigate the Kano categorization, the coefficient of satisfaction and dissatisfaction for the four critical CRs. For each CR, a pair of question is asked, one in functional form and another in dysfunctional form. The questionnaire concerns customers' responses about two extreme cases, nearly $0 \%$ and $100 \%$ fulfillment of each CR. For instance, the pair of questions regarding business performance in the Kano questionnaire is shown in Table 1.

Table 1. Kano Survey Question (Example).

\begin{tabular}{l|l}
\hline \multirow{4}{*}{$\begin{array}{l}\text { If the laptop is very good at basic } \\
\text { office work and surfing, how do }\end{array}$} & $\square$ I like it that way. \\
\cline { 2 - 2 } you feel? & $\square$ I must be that way. \\
\cline { 2 - 2 } & $\square$ I can live with it that way. \\
\cline { 2 - 2 } & $\square$ I dislike it that way. \\
\hline \multirow{4}{*}{$\begin{array}{l}\text { If the laptop is very bad at basic } \\
\text { you feel? }\end{array}$} & $\square$ I like it that way. \\
\cline { 2 - 2 } york and surfing, how do & $\square$ I am neutral. \\
\cline { 2 - 2 } & $\square$ I can live with it that way. \\
\cline { 2 - 2 } & $\square$ I dislike it that way. \\
\hline
\end{tabular}

In order to formulate customer satisfaction (CS) as an expression of the fulfillment level of each CR, D Company conducted the survey among the target users of Company A's products. The survey received 120 responses. Table 2 provides an overview of all five levels of the used range for all four pairs of investigated requirements.

Table 2. Overall positive and negative requirement statistics.

\begin{tabular}{|c|c|c|c|c|c|c|}
\hline Variables & $\begin{array}{l}\text { I would be } \\
\text { thrilled } \\
\text { through }\end{array}$ & $\begin{array}{l}\text { I would } \\
\text { be } \\
\text { satisfied }\end{array}$ & $\begin{array}{c}\text { Neither } \\
\text { satisfied nor } \\
\text { dissatisfied }\end{array}$ & $\begin{array}{l}\text { I would be } \\
\text { dissatisfied }\end{array}$ & $\begin{array}{l}\text { I would } \\
\text { be upset }\end{array}$ & Total \\
\hline
\end{tabular}

\begin{tabular}{lcccccc}
\hline Biz_positive & 33 & 77 & 9 & 1 & 0 & 120 \\
\hline Multimedia_positive & 79 & 19 & 22 & 0 & 0 & 120 \\
\hline Computation_positive & 68 & 29 & 23 & 0 & 0 & 120 \\
\hline Storage_positive & 56 & 29 & 31 & 3 & 1 & 120 \\
\hline Biz negative & 0 & 13 & 13 & 13 & 81 & 120 \\
\hline Multimedia negative & 0 & 5 & 27 & 32 & 56 & 120 \\
\hline computation_negative & 0 & 8 & 42 & 29 & 41 & 120 \\
\hline storage negative & 0 & 6 & 15 & 32 & 67 & 120 \\
\hline
\end{tabular}

Referring to Kano model, the responses are summarized and translated to Kano classification as shown in Table 3. For instance, 61 respondents perceive business performance as a must-be attribute. Therefore, the Kano classification of business performance is ' $\mathrm{M}$ ' for must-be.

Two important values, the coefficient of satisfaction (CS) and the coefficient of dissatisfaction (DS), must be calculated in order to formulate CS as an expression of the fulfilment of CR. The CS of $C R_{i}$, denoted by $C S_{i}$, can be calculated by the sum of 
satisfaction elements (one-dimensional and attractive), divided by all effective responses (excluding 'R' and 'Q'), as shown below by Eq. (3.1):

$$
C s_{i}=\frac{f_{O}+f_{A}}{f_{A}+f_{O}+f_{M}+f_{I}}
$$

where $f_{A}, f_{O}, f_{M}$, and $f_{I}$ is the total number of attractive, one-dimensional, must-be and indifferent responses, respectively.

Similarly, the DS of $C R_{i}$, denoted by $d s_{i}$, can be calculated by the negative sum of dissatisfaction elements (one-dimensional and must-be), divided by all effective responses, as shown below by Eq. (3.2):

$$
d s_{i}=-\frac{f_{O}+f_{M}}{f_{A}+f_{O}+f_{M}+f_{I}}
$$

Table 3. Kano Survey Result.

\begin{tabular}{c|c|c|c|c|c|c|c|c|c|c}
\hline CR & O & A & M & I & R & Q & Total & KC & CS & DS \\
\hline Business Performance & 20 & 13 & $\mathbf{6 1}$ & 26 & 0 & 0 & 120 & M & 0.275 & -0.675 \\
\hline Multimedia Performance & $\mathbf{4 4}$ & 25 & 12 & 29 & 0 & 0 & 120 & 0 & 0.658 & -0.467 \\
\hline Computation Performance & 27 & $\mathbf{4 1}$ & 14 & 38 & 0 & 0 & 120 & $\mathrm{~A}$ & 0.567 & -0.342 \\
\hline Storage & 31 & 25 & $\mathbf{3 5}$ & 28 & 0 & 1 & 120 & $\mathrm{M}$ & 0.47 & -0.555 \\
\hline
\end{tabular}
O: One-dimensional
A: Attractive
M: Must-be

The $\mathrm{x}$ is the fulfillment level of the CR and the $\mathrm{y}$ is the corresponding satisfaction level. The expression of one-dimensional CSs follows a linear function, $y=a x+b$. The expression of attractive CSs and must-be CSs follows a smooth nonlinear function, $y=$ $a e^{x}+b$, and $y=a\left(-e^{x}\right)+b$. According to the result, customer satisfaction is formulated by the equations corresponding to the Kano classification for each customer requirement as shown in Table 4.

Table 4. Formulation of CRs.

\begin{tabular}{c|c|c|c|c|c}
\hline CR & KC & $\boldsymbol{a}$ & $\boldsymbol{b}$ & $\boldsymbol{f}(\boldsymbol{x})$ & $\boldsymbol{S}=\boldsymbol{a} \boldsymbol{f}(\boldsymbol{x})+\boldsymbol{b}$ \\
\hline Business Performance & $\mathrm{M}$ & 1.503 & 0.828 & $-\mathrm{e}^{\mathrm{x}}$ & $\mathrm{S}=-1.503 \mathrm{e}^{\mathrm{x}}+0.828$ \\
\hline Multimedia Performance & $\mathrm{O}$ & 1.125 & -0.467 & $\mathrm{x}$ & $\mathrm{S}=1.125 \mathrm{x}-0.467$ \\
\hline Computation Performance & $\mathrm{A}$ & 0.529 & -0.87 & $\mathrm{e}^{\mathrm{x}}$ & $\mathrm{S}=0.529 \mathrm{e}^{\mathrm{x}}-0.87$ \\
\hline \multicolumn{1}{c|}{ Storage } & $\mathrm{M}$ & 1.622 & 1.067 & $-\mathrm{e}^{\mathrm{x}}$ & $\mathrm{S}=-1.622 \mathrm{e}^{\mathrm{x}}+1.067$ \\
\hline
\end{tabular}

Furthermore, the importance weight of each $\mathrm{CR}$, denoted by $w_{i}$, is required from the service demander. It constitutes the last portion of the optimization framework to get the value of overall customer satisfaction as shown in Figure 2. We could obtain the importance weight from customers. 


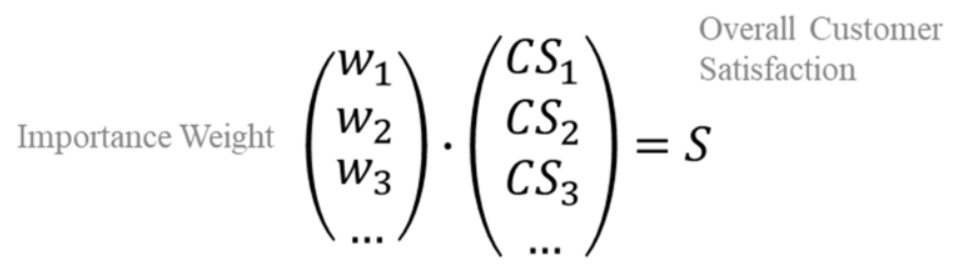

Figure 2. Overall Satisfaction in Optimization Framework.

\section{New scenario of using quick-response product configuration system}

The definition of engineering characteristics (ECs) is built based on Company B's capabilities. CRs and CS-F relationship functions are built based on market research and survey. Under the fundamental support and the backend system calculation, we may propose a new quick-response product configuration system (we use QRPCS hereafter.), which is as depicted in Figure 3. The system would be ready to take customer inputs to recommend the optimal solution. In the to-be model with QRPCS, Company B could response a customer profile given by Company A by using QRPCS. The customer requirements included the expected budget, importance weights of each $\mathrm{CR}$, which are calculated based on the results of Table 4, and other special requests. It could generate an optimal configuration within the budget immediately.

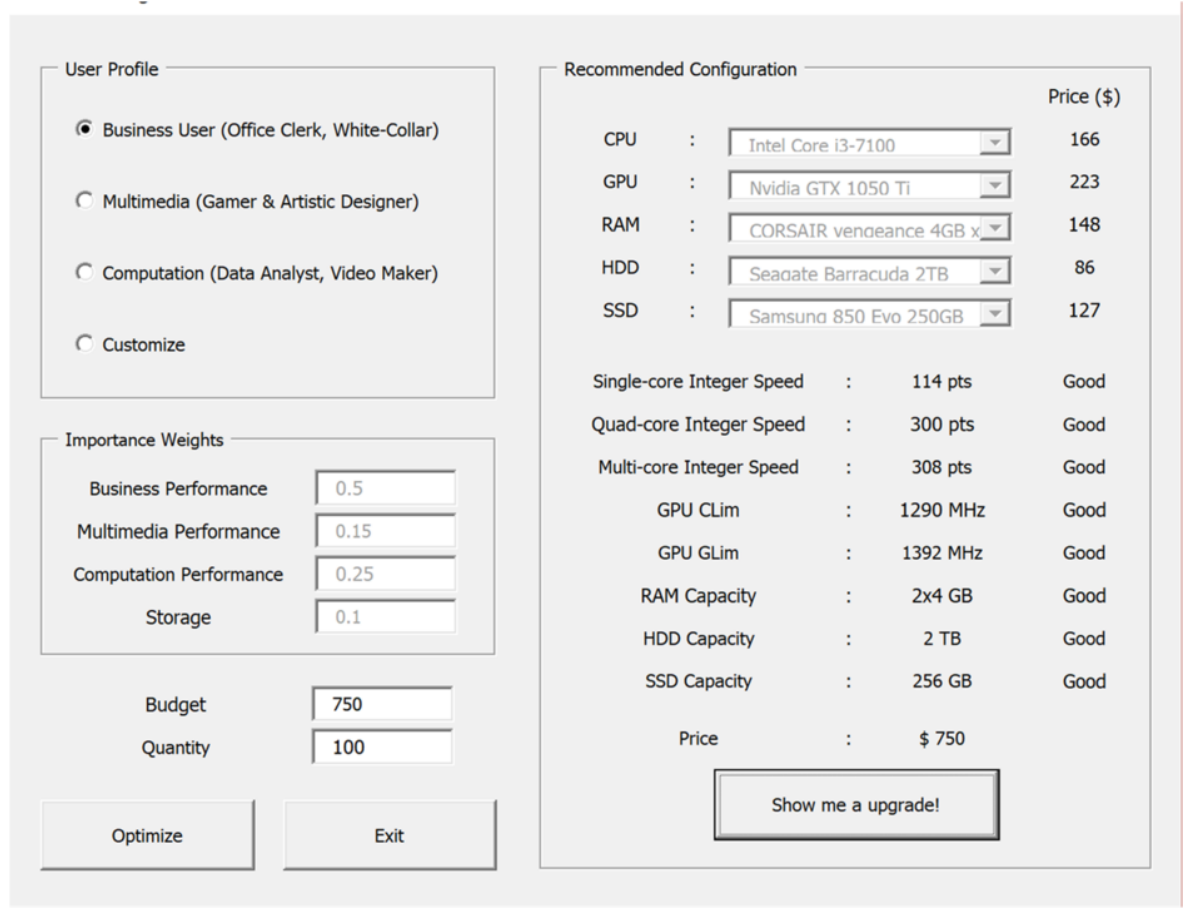

Figure 3. Scrrenshot of the quick-response product configuration system. 
Table 5. Recommended Technical Parameters.

\begin{tabular}{|c|c|c|c|c|}
\hline EC & Selection & Technical Parameter & & \\
\hline \multirow[t]{2}{*}{$\mathrm{CPU}$} & \multirow[t]{2}{*}{ A3 } & $\begin{array}{l}\text { Single-Core Integer } \\
\text { Speed (pts) }\end{array}$ & $\begin{array}{ll}\text { Quad-Core } & \text { Integer } \\
\text { Speed (pts) } & \end{array}$ & $\begin{array}{ll}\text { Multi-Core Integer } \\
\text { Speed (pts) }\end{array}$ \\
\hline & & 114 & 300 & 308 \\
\hline \multirow{2}{*}{ GPU } & \multirow{2}{*}{ B2 } & CLim (MHz) & $\operatorname{MLim}(\mathrm{MHz})$ & \\
\hline & & 1290 & 1392 & \\
\hline \multirow{2}{*}{ RAM } & \multirow{2}{*}{$\mathrm{C} 3$} & Capacity (GB) & & \\
\hline & & $2 \times 4$ & & \\
\hline \multirow[t]{2}{*}{ HDD } & \multirow[t]{2}{*}{ D4 } & Capacity (TB) & $\begin{array}{ll}\text { Sequential } & \text { Read } \\
\text { Speed }(M B / s) & \end{array}$ & \\
\hline & & 2 & 174 & \\
\hline \multirow[t]{2}{*}{ SSD } & \multirow[t]{2}{*}{ E3 } & Capacity (GB) & $\begin{array}{ll}\text { Sequential } & \text { Read } \\
\text { Speed }(M B / s) & \end{array}$ & \\
\hline & & 250 & 497 & \\
\hline
\end{tabular}

For example, Company B approaches Company A to order 100 units of laptops for their customers. The expected budget is around $\$ 1000$ per unit, out of which, $\$ 750$ is allocated to the primary functional ECs (CPU, GPU, RAM, HDD, and SSD). QRPS can assist the response for future and expected scenario of flexible manufacturing under Industry 4.0. It plays a vital role to bridge the communication gap between Company A and Company B as well as speed up the customization process, earning a competitive edge for both parties in Industry 4.0. In the to-be process with QRPS, the production objective of "low volume amount and high mix specification" order requirements can be achieved. The graphic user interface can be shown in Figure 2, and the recommendation results for manufacturing are summarized in Table 5.

\section{Conclusion}

The study attempts to develop an approach to automate this configuration process by taking the voice of customers as inputs with Kano model. This research demonstrates how to use Kano model in a new configure-to-order context under I 4.0. By conducting a marking investigation to formulate CS as an expression of the fulfillment level of CR for the product of laptop. Formulation of four CRs, i.e. business performance, multimedia performance, computation performance, and storage could be obtained. Then, a quick-response product configuration system (QRPCS) was designed based on the results to use the backend optimization procedure for laptop configuration. The work has carried out the outcomes of Kano model on a case study of an empirical manufacturing scenario. The contributions of the paper are consisted of at least two aspects. Firstly, this 
paper provides a Kano-based method that can cope with the order acquisition and fulfillment process. The method can enrich the literature of the Kano model application. Secondly, it also brings a practical case study for product configuration system design. In the future work, evaluation with end users of the QRPCS can be conducted, focusing on the quality of user interaction with the system (i.e. usefulness and usability). It could be adapted to other similar products' configuration processes in the future.

\section{Acknowledgement}

The authors wish to acknowledge the support from the National Research Foundation (NRF) Singapore and Delta Electronics International (Singapore) Pte Ltd., under the Corporate Laboratory@ University Scheme (Ref. SCO-RP1; RCA-16/434) at Nanyang Technological University, Singapore, New Start-up Fund of Xi'an Jiaotong University, under Grant 7121192301.

\section{References}

[1] H. Kagermann, J. Helbig, A. Hellinger and W. Wahlster, Recommendations for implementing the strategic initiative INDUSTRIE 4.0: Securing the future of German manufacturing industry, final report of the Industrie 4.0 Working Group. Forschungsunion, 2013.

[2] M.E. Porter, and J.E. Heppelmann, How smart, connected products are transforming competition, Harvard Business Review, vol. 92, no.11, pp. 64-88, 2014.

[3] C.F. Yuan, W.L. Wang and L.X. Shen, Approach of Customer Requirement Decomposition Based on Requirement Element in Product Configuration Design and its Application, in: Advanced Materials Research, Trans Tech Publ, pp. 2886-2890, 2011.

[4] C.H.Lee, Y.H. Wang and A.J.C. Trappey, Ontology-based reasoning for the intelligent handling of customer complaints, Computers \& Industrial Engineering, vol. 84, pp. 144-155, 2015.

[5] C. Berger, Kano's methods for understanding customer-defined quality, Center for Quality Management Journal, Vol. 2, 3-36, 1993.

[6] P. Ji, J. Jin, T. Wang and Y. Chen, Quantification and integration of Kano's model into QFD for optimising product design, International Journal of Production Research, Vol. 52, No.21, pp. 6335-6348, 2014.

[7] M.G. Violante and E. Vezzetti, Kano qualitative vs quantitative approaches: An assessment framework for products attributes analysis, Computers in Industry, Vol.86., pp.15-25, 2017.

[8] T. Wang and P. Ji, Understanding customer needs through quantitative analysis of Kano's model, International Journal of Quality Reliability Management, Vol. 27, pp. 173-184, 2010.

[9] L. He, W. Song, Z. Wu, Z. Xu, M. Zheng and X. Ming, Quantification and integration of an improved Kano model into QFD based on multi-population adaptive genetic algorithm, Computers Industrial Engineering, Vol.114, 183-194, 2017.

[10] F. Li, C.H. Lee, G. Xu, C.-H. Chen and L.P. Khoo, A QFD-Enabled Conceptualization for Reducing Alarm Fatigue in Vessel Traffic Service Centre, Advances in Transdisciplinary Engineering, Vol. 6, 2017, pp. 821-828.

[11] C.H. Lee, C.H. Chen and A.J.C. Trappey, A structural service innovation approach for designing smart product service systems: Case study of smart beauty service, Advanced Engineering Informatics, vol. 40, pp. 154-167, 2019.

[12] Y. H. Wang, C. H. Lee, and A.J.C. Trappey, Modularized design-oriented systematic inventive thinking approach supporting collaborative service innovations, Advanced Engineering Informatics, vol. 33, pp. $300-313,2017$. 
[13] C. H. Lee, X. Zhao and Y. C. Lee, Service Quality Driven Approach for Innovative Retail Service System Design and Evaluation: A Case Study. Computers \& Industrial Engineering, vol. 135, pp. 275-285, 2019.

[14] F. Li, C. H. Chen, C. H. Lee, and L. P. Khoo, A User Requirement-driven Approach Incorporating TRIZ and QFD for Designing a Smart Vessel Alarm System to Reduce Alarm Fatigue. The Journal of Navigation, 1-21, 2019. 